\title{
Territorial planning of transport in Russia: current condition, problems and prospects of development
}

\author{
Petr Krylov ${ }^{1, *}$ \\ ${ }^{1}$ Moscow Region State University, 10A, Radio str., 105005, Moscow, Russia
}

\begin{abstract}
The paper considers the current condition and problems of territorial planning of extra-urban transport in Russia. The paper analyzes the key parameters of improving the transport system of Russia as one of the most important elements of the economic system. The main social and economic requirements for documents of territorial planning of transport in Russia at the regional level are contained in the regional standards of urban planning design. They set the time limits for maximum transport accessibility from places where people live to places where important social and economic objects and service institutions are located. The paper provides examples of the most important promising projects in the construction of extra-urban transport infrastructure. Similarities and differences between general layouts and master plans in terms of territorial planning of transport infrastructure are shown. The problems of planning transport systems of urban agglomerations are considered. Recommendations are given for changing the methodology of territorial planning of extra-urban transport in Russia.
\end{abstract}

\section{Introduction}

According to a number of scientists, the development of extra-urban transport in Russia, due to its high capital intensity, the complexity of state regulation and the ambiguity of promising strategic development goals, has fallen out of the list of state priorities for many years. Many of the activities in the field of extra-urban transport in modern Russia are not carried out and have not been carried out in time for the last 2-3 decades. Only the need to implement major national projects contributed to the creation of major infrastructure projects: the construction and commissioning of "Platov" airport near Rostov-on-Don, "Gagarin" airport near Saratov, bridge passages in Vladivostok (including to Russky island), and others.

In terms of the pace of commissioning of new facilities and individual sections of roads and railways, Russia today lags behind not only the majority of developed countries, but also of Kazakhstan and the republics of Central Asia. However, the gap may not be considered as large if we take into account the commissioning of sections of non-public roads, such as construction by "Gazprom" on the Yamal Peninsula, by "Mechel" company

\footnotetext{
*Corresponding author: pmkrylov@yandex.ru
} 
in the Republic of Sakha (Yakutia), and others. Built sections of public railways, extending over one hundred kilometers, since 1992 we can also name a few: a built section of the railway in Yakutia (Amur-Yakutsk Mainline), about $800 \mathrm{~km}$ long, belonging to the "Railways of Yakutia" - the largest transport project for this period; the recently commissioned railway bypass of Ukraine in the Voronezh and Rostov regions (136 km), as well as the Kochkoma - Ledmozero section in the Republic of Karelia (132 km), opened in 2008 .

Territorial planning is an important function and task for state and municipal authorities to create conditions for the promising development of territories of various levels, taking into account certain opportunities and limitations. The goals, tasks and responsibilities of Russian state and local authorities for creating and changing territorial planning documents are detailed in the Urban planning code of Russia and other legal documents [1]. Part of territorial planning is the accounting and prospective development of extra-urban transport infrastructure, including linear (network), local and point objects.

\section{Results and discussion}

The main tasks for the development of the country's transport system in the "Transport strategy of the Russian Federation", for the period up to 2030 are named as follows [2]:

1) formation of a unified transport space in Russia based on the balanced development of efficient transport infrastructure;

2) ensuring the availability, volume and competitiveness of transport services for cargo owners in accordance with the needs of innovative development of the country's economy;

3 ) ensuring the availability and quality of transport services for the population in accordance with social standards;

4) integration into the global transport space and implementation of the country's transit potential;

5) improving the security of the transport system;

6) reducing the harmful impact of transport on the environment;

7) development of transport equipment, technologies and information support;

8) regional aspect of the development of the Russian transport system.

It should be noted that the transport policy of most countries with a socially oriented market economy is currently aimed at increasing the share of public transport and slowing the growth of the fleet of individual (personal) transport. There was also a tendency to increase the role of rail transport in the transport infrastructure in the $90 \mathrm{~s}$ years. The forms of organization and development of urban transport infrastructure should be regulated by the ultimate goals of its existence - the general welfare, including consideration of the interests of future generations. Hence the connection of this process with sustainable development in a broad sense. The concept of the city's social and transport standard reflects this connection [3]. The future of transport infrastructure depends on what priorities are set at the territorial planning stage. These priorities include:

1) fulfillment of social obligations towards those segments of the population that do not have individual transport;

2) maintaining or improving the economic stability of the served areas so that public transport and road network, as well as related infrastructure, do not become a burden for the municipal budget;

3) minimizing the negative impact of transport infrastructure on the environment. 


\section{Ratio of general layouts and master plans}

Documents of territorial planning in the Soviet period, including General layouts, at a time when all capital construction objects belonged to the state, were implemented in close connection with budget financing. However, in the conditions of the formed market economy of modern Russia and the growing role and importance of private initiative and private capital, it is quite natural that society and business have requested a new form of strategic planning that has existed for a long time in developed countries - the so-called master plans. The master plan, which has come into use in Russian urban planning in recent years, in a generalized form is a set of the most significant and investment-attractive promising capital construction projects, the implementation of which is possible and necessary on a specific territory in the near or medium term.

In accordance with modern concepts, the master plan is another form of spatial development strategy for the territory (along with regional and country-wide program documents that have the same wording in the name in whole or in part). It is created by the relevant authorities, but with the help of experts, taking into account the interests of various groups (both local residents and business entities of different levels), and assumes selectivity - the focus is only a small number of priorities and territories (sites) for development.

Among representatives of modern theory and practice of urban planning, there is a mixed opinion about the role and ratio of territorial planning and master plans. $[4,5,6,7]$.

We will further highlight several of their common and different characteristics. Thus, the general layout in accordance with the provisions of the Urban planning code, primarily regulates land use processes, being in one form or another a technical document for specialized specialists, while the master plan contains only the directions of conceptual development that allow identifying key problems and points of change in the development of the territory.

The master plan in its modern sense is designed primarily for established cities, while the general layout is intended more for the development of poorly developed territories; it contributes less to improving the efficiency of the existing territory, but it is always suitable for the task of increasing its capitalization.

It can also be noted that the master plan is a document that, unlike the general layout, prescribes to build not "where and what", but "what and how". A master plan, in contrast to a general layout, usually contains an economic justification for the plan of commissioned facilities: who and at whose expense will carry out construction in the city and what benefits it will bring to the city and its residents in the future. It should also be noted that in the narrow sense in the master plan, the section related to transport infrastructure may not exist at all.

Master plans need to attract investment, they did not cover the whole town (whole territory of the region). However, a significant difference is that master plans are not needed to maintain the existence and transformation of a shrinking city. One of the most pressing problems of regional development in recent years is the controlled compression of cities. To support cities with declining populations and production, general layouts are needed, but not master plans. For example, the concept of managed city compression applies to the city of Vorkuta. The closure of the mines leads to the closure of the village. The situation can be corrected, for example, by organizing extra-urban bus routes between "dying" villages and the central districts of Vorkuta that have saved jobs.

General layouts in modern Russian conditions take into account short-term and very rarely medium - and long-term plans for creating transport infrastructure of regional or federal significance. It should be noted that the development of extra-urban transport infrastructure for the future (for a period of 5-10 years) was previously developed using 
integrated transport schemes (ITS). Now they have been replaced by new planning documents in the field of short-and medium-term development of extra-urban transport infrastructure: TMS (integrated traffic management system), ISPTS (integrated scheme for public transport services) and PIDTI (project for integrated development of transport infrastructure). However, these project documents only "adjust" to the non-transport components of territorial planning (development of residential and industrial territories, the intensity of economic activity in general, etc.).

The transport component of the territorial planning of a region, urban district, rural or urban settlement, as well as an agglomeration, is the most important planning component that determines the internal and external connectivity of the territory.

In contrast to the master plan, the transport component of the general layout usually describes in detail the directions of not only internal, but also external (extra-urban) development of the territory's transport infrastructure in conjunction with regional and federal territorial planning documents.

The general layouts of urban districts need to be updated in a timely manner. One of the problems of modern territorial planning in Russia as a whole is the discrepancy between the needs of municipalities and society as a whole and the timely adjustment of urban planning documentation. The process of developing the transport component in territorial planning is significantly hindered by imperfect legislation, low responsibility of the customer, including municipal authorities for the quality and volume of providing source data. Moreover, transport statistics (including state, municipal, and corporate (departmental)) do not contribute to the creation of a high-quality document. Its disadvantages include the almost complete absence of indicators that reflect the volume of cargo and passenger traffic on certain sections of the road network. Most of the indicators that reflect the current state of transport infrastructure are collected by the developers of the territorial plan themselves. However, local authorities are not always willing and able to provide the necessary information. Federal authorities and major Russian monopoly corporations (for example, Russian Railways) often do not provide information about long-term plans for creating transport infrastructure, except for the objects included in the companies' investment strategies.

One of the key problems of general layouts, which is also transferred to master plans, is the complete or partial disregard of the relevant authorities for the previously adopted and approved provisions of these documents. The length and cost of construction of extra-urban transport infrastructure has always affected the non-implementation of territorial planning proposals.

In relation to extra-urban transport infrastructure (capital-intensive and low-profitable from a formal economic point of view), private capital is often not interested in elements of the road environment (roads, bridges and overpasses), except for the possibility of creating objects on the terms of public-private partnership. The creation (design, construction) and operation of auxiliary transport and road infrastructure are interested: gas stations, campsites, paid parking spaces, etc., which are usually taken into account in the framework of general layouts of cities, but can also be taken into account in master plans. At the "right" moment, not without the participation of local authorities, it was often possible to ignore the construction of the designed section of the road network, giving the reserved area, for example, for multistory commercial residential construction.

Creating master plans in Russian conditions does not yet solve (unlike general layouts) the problems of social and transport standards for a specific territory. So, one of the methodological problems of territorial planning of extra-urban transport, as well as the geography of transport in general, can be considered the lack of a unified, reasonable and generally accepted method for assessing the transport security of the territory of particular 
levels, and the lack of method for determining the transport and geographical position of the territory as a whole, or individual object (settlement, transport communications).

Table 1 below shows the ratio of Russian general layouts to master plans for transport infrastructure.

Table 1. The ratio of general layouts and master plans in Russia (in relation to transport infrastructure).

\begin{tabular}{|c|c|c|}
\hline Characteristic & General layout & Master plan \\
\hline $\begin{array}{l}\text { Accounting for the long-term } \\
\text { development of the city's } \\
\text { territory, its transport and non- } \\
\text { transport components }\end{array}$ & Yes & $\begin{array}{l}\text { Yes, but the role and significance } \\
\text { of the transport factor may differ } \\
\text { in individual documents }\end{array}$ \\
\hline $\begin{array}{l}\text { Compliance with the provisions } \\
\text { of the urban development code } \\
\text { of the Russian Federation and } \\
\text { other regulatory documents }\end{array}$ & Yes & $\begin{array}{l}\text { Not obligatory (not necessarily in } \\
\text { full) }\end{array}$ \\
\hline $\begin{array}{l}\text { Considering the local and } \\
\text { regional standards of urban } \\
\text { planning design }\end{array}$ & Yes & Not obligatory \\
\hline $\begin{array}{l}\text { Availability of graphic and text } \\
\text { parts }\end{array}$ & Yes & Not obligatory \\
\hline $\begin{array}{l}\text { For newly approved documents } \\
\text { (as of 01.01.2019), the } \\
\text { cartographic part is based on } \\
\text { Order No } 10 \text { of the Ministry of } \\
\text { Economic Development of the } \\
\text { Russian Federation dated } \\
09.01 .2018 \text {. }\end{array}$ & Yes & No \\
\hline Level of displayed objects & $\begin{array}{l}\text { It is mandatory to } \\
\text { display items of local } \\
\text { significance }\end{array}$ & Not specified \\
\hline Need for constant adjustments & $\begin{array}{l}\text { The legislation does not } \\
\text { specify a clear time } \\
\text { frame }\end{array}$ & No \\
\hline Quick adjustment option & No & Yes \\
\hline Planning horizon & At least 20 years old & Not specified \\
\hline $\begin{array}{l}\text { The need to coordinate the } \\
\text { provisions with the authorities }\end{array}$ & Yes & $\begin{array}{l}\text { Not required (except for the } \\
\text { customer) }\end{array}$ \\
\hline
\end{tabular}

Transport accessibility is reflected in the basic law on general principles of local selfgovernment organization (131-FZ). Federal law "On general principles of local selfgovernment organization in the Russian Federation" dated 06.10.2003 N 131-FZ. So, in article 11 (about borders of municipalities) it is said that borders of the city district, municipal district are allocated taking into account transport accessibility to their administrative centers and back during the working day for residents of all settlements (localities) that are part of them [8]. In accordance with the laws of the constituent entities of the Russian Federation, these requirements may not be applied in areas with a low rural population density, as well as in remote and hard-to-reach areas.

In the current version of the transport strategy of Russia until 2030, for the first time, two of the eight goals (see above) are named "improving the transport accessibility", which corresponds to the principles of sustainable development.

This means consistent improvement in transport performance indicators observed primarily in the properties of the territory (availability of social and economic objects, reduction of transport costs, environmental friendliness of places of residence, and other 
properties, formed by the transport system of the region or the country as a whole that future generations will inherit).

\section{Territorial planning of extra-urban transport in Russian agglomerations}

One of the modern trends is the growing concentration of population and productive forces in urban agglomerations. The creation of project documents for urban agglomerations that are part of various subjects of the Russian Federation remains a complex and unresolved problem of territorial planning of transport and transport infrastructure in Russia. In Russia, there are still no clear requirements for the actual territorial planning of urban agglomerations at the current level, and the requirements for approving such design and planning works.

This is also reflected in the existence of numerous territorial planning projects for transport systems in Russian agglomerations. It should be noted that the Urban planning code of the Russian Federation and many other legal documents in the field of territorial planning and urban development do not notice (with rare exceptions) urban agglomerations as objects of territorial planning. Many large Russian cities and urban districts (their management) usually understand "agglomeration works" in the field of territorial planning as a justification for further territorial expansion of a large city.

At the junction of municipalities in agglomerations, conflict situations arise due to the need to resolve issues of removing transport infrastructure from a large city, or creating additional transport infrastructure in the surrounding area (bypass roads, transport and logistics complexes, etc.). The need to remove federal objects from a large city (especially railway transport objects) is usually encountered by the departmental interests of JSC "Russian Railways", which does not need extra hassle.

As a result, major cities such as Khabarovsk, Makhachkala, Vladimir and many others are "cut" by partially isolated sections of railways.

It should also be noted that, in our opinion, the goal of the development of transport systems in agglomerations can't be considered a further increase in the concentration of economic activity and population in the cores of agglomerations. Such a result can be considered negative, since the excessive concentration of population and economy in a small area of agglomerations simultaneously contributes to the appearance of "economic deserts" in large areas in other regions of Russia.

Norms and regulations in territorial planning of extra-urban transport in Russia.

The use of norms, regulations and recommendations is an integral part of design and planning work in the field of territorial planning and urban development in Russia as a whole, as well as in the field of transport infrastructure. However, in addition to SNiPs and SanPiNs (Federal regulations), urban planning design standards are used that apply only to a specific region (a subject of the Russian Federation or a municipality).

One of the problems of modern federalism in Russia, which is manifested, among other things, in the transport infrastructure of regions, is the unequal financial opportunities of the subjects of the Federation in the implementation of transport policy at the regional level [9, 10]. Local social and economic, natural and geographical and other specifics of regions in the field of promising development are taken into account, including in regional urban planning standards. The main social and economic requirements for documents of territorial planning of transport in Russia at the regional level are contained in the regional standards of urban planning design (RSUD). As a rule, the RSUD sets the time limits for maximum transport accessibility from places where people live (localities with different population density) to places where important social and economic objects and service institutions are located (boarding schools, schools, large medical centers, emergency medical stations), etc. 
However, Russia currently does not have uniform standards for transport accessibility of socially significant objects, as it was during the USSR period. Each of the regions can now adopt such standards at its own discretion. Relatively more "poor" regions that save their budget, including on transport infrastructure, are forced to revise their RSUD in the direction of deterioration of the maximum permissible standards of transport accessibility. As a result, the standards for transport accessibility (both private and public transport) of socially important objects in them are increasing, and the need for these socially important objects is underestimated, and in some cases, they can even be closed according to this criterion. At the same time, relatively more "rich" regions may set less stringent standards, with more favorable design indicators for the availability of socially significant objects for the population.

Local (municipal) standards for urban planning (LSUD) are also created and implemented on the basis of the RSUD, which are necessary for creating design and planning works at the level of municipalities (including territorial planning schemes for municipal districts, general layouts for urban districts, rural and urban settlements).

In addition to the RSUD at the municipal level, certain regions of the Russian Federation have maintained the region's overall performance indicators for municipalities, including those related to transport infrastructure.

This may include, for example, the percentage of localities that do not have access to paved roads, or the percentage of localities that are not served by external public transport. Achieving these indicators can serve as a supplement to, but not a substitute for, regional urban planning standards. The set of similar indicators differs significantly between regions of Russia.

The variety of regional and municipal standards for urban planning in Russia is difficult to analyze. The standards themselves are developed by many different organizations, taking into account the specifics of the planned territory.

It should be noted that municipal regulations apply only within the borders of this municipality, while regional regulations apply on the territory of all municipalities of the corresponding subject of the Russian Federation, including inter-settlement territories. Therefore, regional regulations should be more thoughtful, taking into account the specifics of different parts of a particular region (taking into account that the LSUD have not yet been developed at all for many municipalities).

The development of Russia in modern conditions dictates the need for accelerated development (including territorial planning) of transport infrastructure. However, the legal documents regulating this activity do not require the development of the following types and forms of transport work:

1) growth in the number of motor vehicles using gas-engine fuel;

2) development of road transport infrastructure using electric energy (and related infrastructure);

3) development of self-driving vehicles (with related infrastructure);

4) taking into account the geopolitical factor and new international projects (connecting China, Central and East Asian countries with Europe).

From a transport and geographical point of view, modern Russia does not prioritize the importance and timing of the design and commissioning of the following major projects (they appear and disappear from federal industry regulatory documents):

1) construction of $\mathrm{Ob}$ river bridges (in Salekhard), Lena (in Yakutsk), Aldan (on the "Yakutsk-Magadan" highway);

2) construction of a tunnel (or bridge) to Sakhalin island;

3) construction of the railway section from Cherkessk to Sochi;

4) construction of separate sections of the Belkomur railway project; 
5) construction of road and railway bypasses of large and strategically important cities, transport hubs;

6) ensuring transport accessibility of socially significant objects (including within the framework of the "Far Eastern hectare" program in the Far East).

In Russian territorial planning, it is quite difficult to combine general layouts and territorial planning schemes with local and regional standards for urban planning. In fact, they are not an instrument of territorial development, but a justification for the weak development of social infrastructure through the possible promising development of transport infrastructure. For example, many of these regulations relate to the low availability of kindergartens, schools, ambulance stations, hospitals, etc. with the growth (improvement) of transport accessibility, which is largely not achievable in the near future. In regions that are relatively poorer in terms of budget availability, it is transport accessibility that justifies the decreasing provision of residents with social infrastructure facilities of regional significance [8]. Therefore, unrealistic transport projects and unattainable results in the area of providing the territory and its inhabitants with transport infrastructure often worsen the result of territorial planning, making it less feasible. However, they also allow regional and local authorities, as well as investors, to justify nontransport investments (including housing construction in poorly developed territories).

The basis for visualization of objects and elements of transport infrastructure for cartographic parts of general layouts, detailed planning projects, territorial planning schemes and other types of design and planning documents until 2018 was the order of the Ministry of Economic Development of the Russian Federation dated 07.12.2016 No 793 "On approval of requirements for the description and display in territorial planning documents of Federal, regional and local objects" [11].

Unfortunately, its content does not significantly reflect the needs of users of project documentation, nor the achievements of science and practice in the field of extra-urban transport. Despite the fact that the above-mentioned order was approved only about three years ago, its content does not reflect many modern realities in the field of urban planning [12]. Thus, it does not take into account electric filling stations for electric vehicles, which are mandatory for planning in Russian cities since the end of 2016. (since 01.11.16, Russian Government Decree No 890 of August 27, 2015 came into force, which states that all gas stations in Russia must be equipped with charging columns for electric vehicles) [13]. For large-scale maps, there are no signs of traffic lights. There is also no such object as a taxi fleet. In the field of railway transport infrastructure, there are no such items as stopping points (we can only use icons corresponding to different types of stations and terminals).

In the field of inland water transport, the concept of a river port and river pier is used, while the concept of a river station is not used. There are icons for the yacht club and boat station, but concepts such as "marine" or "boathouse" are not used.

Transport infrastructure as part of the general layout is displayed on maps in accordance with the requirements of order No 10 of the Ministry of Economic Development of Russia dated 09.01.2018 [14]. This order does not regulate which objects should be displayed on maps as a whole or at different scales. Therefore, many general layouts for transport infrastructure facilities are not comparable not only with other general layouts, but also with urban planning documentation of a different hierarchical level (territorial planning schemes, projects of detailed planning of city districts, etc.).

An important question of territorial planning of extra-urban transport: who and how should evaluate the final result of transport work or the very fact of the presence of certain transport infrastructure objects? The population, transport companies, authorities and cargo owners - are all interested in different final performance indicators of the transport system [15]. 
Excessive transport work is harmful for cargo owners and for the environmental situation, but it also brings additional profit to transport companies. A concomitant factor complicating territorial planning is the division of transport infrastructure into levels (all Russian, regional, local, etc.), by affiliation to the state (Federal, regional), municipal, private, and mixed ownership.

The priority of development of extra-urban transport infrastructure is often determined not by the final social and economic effect for a particular territory, but by the available level of project financing and budget security of a subject of the Russian Federation or a separate municipality.

At the regional level, the most important areas of transport development may include the development of a modern efficient transport infrastructure that provides acceleration of passenger flows, goods movement, and reduction of transport costs in the economy [16].

\section{Conclusions}

Thus, the territorial planning of extra-urban transport in Russia needs further reform, both from a scientific and methodological and practical point of view. Prospective development of extra-urban transport infrastructure can and should be presented in various design and planning documents, one of which, the most significant, should remain the general layout, along with the recently appeared master plan.

Master plans are more suitable and can be to some extent a substitute for general layouts for small and medium-sized cities, whose development prospects for 20-40 years ahead are less obvious than large and largest cities (especially if we are talking about single-industry towns). The master plan cannot be a complete replacement for the general layout. However, general layout, their development and use in urban planning practice need to be further adjusted. To improve the quality and effectiveness of territorial planning (including in relation to extra-urban transport infrastructure) in our opinion, it is necessary:

1) to change approaches to displaying objects and individual elements of transport infrastructure in the graphic and text parts of urban planning documentation for territories of different levels and types;

2) to define more precise requirements for the content of local and regional standards of urban planning design; standards should be interlinked with SNiPs (building rules and regulations) and SanPiNs (sanitary rules and regulations), as well as with Russian and international standards of quality of life;

3) to increase the publicity of decisions taken, as in the current form, the role of public hearings is not sufficient for making a balanced and informed decision [17];

4) to involve and use project solutions in the development of territorial planning documents, taking into account the interests of interested parties, including business. For example, in relation to transport, the issue of designing and building roads, cable cars, railways, airports and other major projects on the terms of public-private partnership is very relevant;

5) to increase the speed of creating and adjusting the general layout (without losing the requirements for its strict implementation) - ideally, it should become a "living organism", rather than rigid drawings with accompanying texts (justifying and approving materials), supplemented by an infinite number of notes and appendices;

6) to divide the functions, tasks, and scope of application for master plans and general layouts; to retain the function of greater publicity and freedom in creating and formatting the document for master plans.

\section{References}


1. Urban Planning code of the Russian Federation from 29.12.2004 N 190-FZ

2. Order of the Government of the Russian Federation of 22.11.2008 N 1734-p "On the Transport strategy of the Russian Federation"

3. V.N. Bugromenko, A.M. Badalian, L.P. Ryzhova, A.V. Ruzskiy, M.Y. Kalinchikov, P.M. Krylov, White book of the Ministry of Transport and Road Economy of the Republic of Tatarstan (M., Palitraprint, 2005)

4. A.K. Bratishchev, Science, education and experimental design. Proceedings of the Moscow Architectural Institute: materials of international scientific and practical conference (Moscow, Moscow Architectural Institute, 2015)

5. E. Vasilyeva, A. Mottaeva, E3S Web of Conferences 91, 08051 (2019) doi.org/10.1051/e3sconf /20199108051

6. E .O. Starodubtseva, Bulletin of the Perm National Research Polytechnic University. Urbanistika 4(8), 7 (2012)

7. V.P. Stepanov, A.V. Galeev, S.V. Shklyaev, P.E. Manokhin, Social and economic management: theory and practice 2, 113 (2018)

8. Federal law "On general principles of local self-government organization in the Russian Federation” dated 06.10.2003 N 131-FZ

9. P.M. Krylov, Diversity as a factor of territorial development. Collection of 30 papers of the economic and geographical session of MARS. Part 1 (M., Eslan, 2014)

10. P. Krylov, MIzvestiya RAS. Geographical Series 4, 66 (2007)

11. V. Holodkova, A. Mottaeva, T. Pokrovskaya, E3S Web of Conferences 164, 11043 (2020) https://doi.org/10.1051/e3sconf /202016411043

12. P.M. Krylov, Social and economic problems of development and functioning of transport systems of cities and zones of their influence. Materials of the XXIV International scientific and practical conference (Minsk, BSTU, 2018)

13. A. Mottaeva, E. Vasilyeva, MATEC Web of Conferences 239, 04019 (2018) doi.org/10.1051/matecconf/201823904019

14. Order of the Ministry of Economic Development of the Russian Federation No 10 of January 9 (2018)

15. S.A. Tarkhov, V.N. Bugromenko, Izvestiya RAS. Geographical Series 5, 127 (2010)

16. I.A. Semina, Bulletin of the Mordovian University 4, 103 (2015)

17. I.N. Volkova, P.M. Krylov, Bulletin of the Moscow State Regional University. Series: Natural Sciences 3, 52 (2018) 